\title{
An easy and versatile 2-step protocol for targeted modification and subcloning of DNA from bacterial artificial chromosomes using non- commercial plasmids
}

\author{
Heiner Hartwich ${ }^{1 *}$ and Hans Gerd Nothwang ${ }^{1,2}$
}

\begin{abstract}
Background: Promoter-specific expression of foreign DNA in transgenic organisms often relies on bacterial artificial chromosomes (BACs). This approach requires modification and subcloning of BAC-DNA by recombineering technologies in Escherichia coli. Most current protocols rely on commercial kits or isolation of BACs, their transfer between different host strains, and their restriction.

Findings: In this report we present a 2-step protocol for efficient modification and subcloning of DNA from bacterial artificial chromosomes using the non-commercial plasmids pKM208 and pTP223, distributed from addgene.com. A targeting cassette was successfully integrated into a BAC and $42 \mathrm{~kb}$ of this construct were subcloned. Both a plasmid-derived substrate with longer homology arms and a PCR-generated substrate with short homology arms (50 bp) were used for recombination. pKM208 and pTP223 contain all required genes for recombineering, but differ in their antibiotic resistance genes. This makes the system independent of the selection markers on the DNA molecules targeted for recombination.

Conclusions: The time and cost saving protocol presented here compares favorably to currently used systems. Using non-commercial plasmids, it allows targeted modification and cloning of large DNA (> $40 \mathrm{~kb}$ ) fragments in vivo without restriction and ligation. Furthermore, both steps are performed in the same host eliminating the need to isolate BAC DNA and to use different bacterial strains.
\end{abstract}

\section{Background}

Bacterial artificial chromosomes (BACs) are low copy plasmids based on the F-plasmid of E. coli. They can carry up to $300 \mathrm{~kb}$ of foreign DNA. The large insert size has made BACs an important source for the generation of transgenic organisms, because they carry entire genes including their regulatory elements. This can be used to express foreign genes in a spatiotemporal pattern, which mimics endogenous gene expression [1-4]. BACs are propagated in recombination deficient $E$. coli strains to achieve high clonal stability and low rate of chimerism.

\footnotetext{
* Correspondence: heiner.hartwich@uni-oldenburg.de

1 Department of Neurogenetics, Institute of Biology and Environmental Sciences, Carl von Ossietzky University, Carl-von-Ossietzky-Straße 9-11, 26129 Oldenburg, Germany

Full list of author information is available at the end of the article
}

Methods to introduce genetic modifications into BACs such as insertions, deletions, or point mutations are primarily based on homologous recombination between the $\mathrm{BAC}$ and targeting molecules and do not require restriction endonucleases or DNA ligases. The most popular approach for the in vivo manipulation of DNA molecules is called recombinogenic engineering or simply recombineering $[5,6]$. Two main recombineering systems are currently employed. One system is based on the proteins RecE and RecT from the prophage Rac [7]. The second system makes use of Red $\alpha, \operatorname{Red} \beta$, and $\operatorname{Red} \gamma$, encoded by the $\lambda$ phage Red operon [8]. The exonucleases RecE and Red $\alpha$ generate ssDNA overhangs, to which the DNA annealing proteins $\operatorname{Rec} T$ and $\operatorname{Red} \beta$ bind. The interaction between RecE and RecT or their functional analogues $\operatorname{Red} \alpha$ and $\operatorname{Red} \beta$ is required to initiate recombination between short homologous regions. Finally, Red $\gamma$ prevents 
the RecBCD-dependent degradation of the targeting DNA molecule [9].

Recombineering systems have been used to engineer the chromosome of E. coli [7,8,10-12], the chromosome of other bacterial pathogens such as Serratia, Shigella, Yersenia, Salmonella and Pseudomonas [13-17], and to manipulate BACs $[18,19]$. For BAC manipulation, two major systems exist. One is the commercially available Red/ET ${ }^{\circledR}$ system from Gene bridges. The second one consists of a publically available system developed by Copeland and coworkers [19], and requires isolation and transformation of BACs into different host strains.

Here we employ successfully the non-commercial plasmids pKM208 and pTP223 (available from addgene.com) in an easy 2-step recombineering protocol. Both plasmids contain the open reading frames for $\operatorname{Red} \alpha, \operatorname{Red} \beta$ and $\operatorname{Red} \gamma$, but differ in the origins of replication and the selection markers. The low copy plasmid pKM208 has the temperature-sensitive origin pSC101 and confers ampicillin (Ap) resistance, whereas the high copy plasmid pTP223 confers resistance to tetracycline (Tc) [12]. Both plasmids express constitutively the LacI repressor for isopropyl $\beta$-D-1-thiogalactopyranoside (IPTG) inducible expression of the recombination enzymes [12]. This feature is useful to estimate the false positive rate by analyzing non-induced cells, and to shut down the recombination system after successful recombineering to minimize undesired rearrangements. We exemplified the successful use of these plasmids by replacing the open reading frame (ORF) of Math5 (murine atonal homologue 5) in the BAC RP23$328 \mathrm{P} 3$ by a CreERT ${ }^{2}$-Neo cassette and subsequent subcloning of the novel $42 \mathrm{~kb}$ transcription unit by gap repair (Figure 1).

\section{Materials and methods \\ Transformation of BAC hosts with Red-expressing plasmids}

A $20 \mathrm{ml}$ culture from a single BAC carrying host colony was grown to an $\mathrm{OD}_{600 \mathrm{~nm}}$ of 0.5 in the presence of chloramphenicol $(\mathrm{Cm})(12.5 \mu \mathrm{g} / \mathrm{ml})$ on a shaker at $37^{\circ} \mathrm{C}$. After centrifugation at $6,000 \mathrm{rpm}$ for $10 \mathrm{~min}$, cells were resuspended in $20 \mathrm{ml}$ precooled deionized water. After another round of centrifugation, cells were resuspended in $50 \mu \mathrm{l}$ precooled deionized water and electroporated with $100 \mathrm{ng}$ of pKM208 ([12]; addgene.com, plasmid 13077) or pTP223 ([20]; addgene.com, plasmid 13263) using a Gene Pulser (Bio-Rad Laboratories, Munich, Germany). Thereafter, pKM208 electroporated cells were incubated in $1 \mathrm{ml} \mathrm{LB}$ broth for $1 \mathrm{~h}$ at $30^{\circ} \mathrm{C}$ to account for the temperature-sensitive origin of replication, whereas pTP223 containing cells were incubated at $37^{\circ} \mathrm{C}$. After plating, the selective LB-agar plates were incubated at the appropriate temperatures $\left(30^{\circ} \mathrm{C}\right.$ or $\left.37^{\circ} \mathrm{C}\right)$.
Preparation of electrocompetent cells for recombination experiments

BAC hosts carrying pKM208 were grown at $30^{\circ} \mathrm{C}$ in $50 \mathrm{ml} \mathrm{LB}$ broth, containing $\mathrm{Cm}(12.5 \mu \mathrm{g} / \mathrm{ml})$ and $\mathrm{Ap}$ $(100 \mu \mathrm{g} / \mathrm{ml})$, whereas BAC hosts carrying pTP223 were grown at $37^{\circ} \mathrm{C}$ in the presence of $\mathrm{Cm}(12.5 \mu \mathrm{g} / \mathrm{ml})$, kanamycin $(\mathrm{Km})(25 \mu \mathrm{g} / \mathrm{ml})$ and $\mathrm{Tc}(10 \mu \mathrm{g} / \mathrm{ml})$. After they reached an $\mathrm{OD}_{600 \mathrm{~nm}}$ of $0.2-0.3$, cultures were split into two $25 \mathrm{ml}$ cultures. One culture was supplemented with IPTG to a final concentration of $1 \mathrm{mM}$, whereas the other culture served as a negative control. After $1 \mathrm{~h}$ of shaking, cells containing pKM208 were heat-shocked for $15 \mathrm{~min}$ at $42^{\circ} \mathrm{C}$ and kept on ice to stimulate subsequent gene replacement [12]. This step was omitted for cultures containing pTP223. After centrifugation of $20 \mathrm{ml}$ culture at 6,000 rpm for $10 \mathrm{~min}$, cells were resuspended in $20 \mathrm{ml}$ precooled deionized water. This step was repeated once. Finally, cells were resuspended in $50 \mu \mathrm{l}$ precooled deionized water and kept on ice until use.

\section{Generation and of the plasmid-derived targeting cassette for modifying the BAC}

The plasmid pMath5-CreERT ${ }^{2}$-Neo was constructed by cloning a PCR product containing the CreERT ${ }^{2}$-Neo from pl451-CreERT ${ }^{2}$ into pMECA [21]. This CreERT ${ }^{2}$-Neo cassette was flanked by two homology arms derived from the Math5 gene of the BAC RP23-328P3. After validation by sequencing, a 5,107 bp long fragment, containing CreERT ${ }^{2}$ $\mathrm{Neo}$ and flanking 708 bp and 372 bp long homology arms, was released by restriction with DraI (MBI Fermentas, St. Leon-Rot, Germany) and gel-purified using peqGOLD Gel Extraction Kit (Peqlab, Erlangen, Germany).

\section{PCR based generation of a pBR322-derived targeting cassette for subcloning}

To generate the targeting cassette for subcloning, a PCR was performed with Phusion-Polymerase (New England Biolabs, Frankfurt am Main, Germany) using pBR322 as template and the primers pBR322-Math5-R 5'-TGTCTCC CACAGTACCTAACATAGGATCTTACAGAGTAGACAC ACATGATGTTTAAACGATACGCGAGCGAACGTG-3' and pBR322-Math5-L 5'-CCTGCAGCACAGCCTCCAACAGTTTTCAGTCTACTCATCTTTCCTAGTATGTTTAAACTTAGACGTCAGGTGGCAC-3' (an $M s s$ I site is underlined, Math5 homology regions are in italics). After DpnI (MBI Fermentas) restriction, the PCR product was gel-purified using peqGOLD Gel Extraction Kit (Peqlab) and eluted with deionized water.

\section{Electroporation of targeting constructs}

The gene targeting DNA (300 ng) was mixed with $50 \mu \mathrm{l}$ of cell suspension and put into a precooled $0.1-\mathrm{cm}$ electroporation cuvette and electroporated with a Gene 


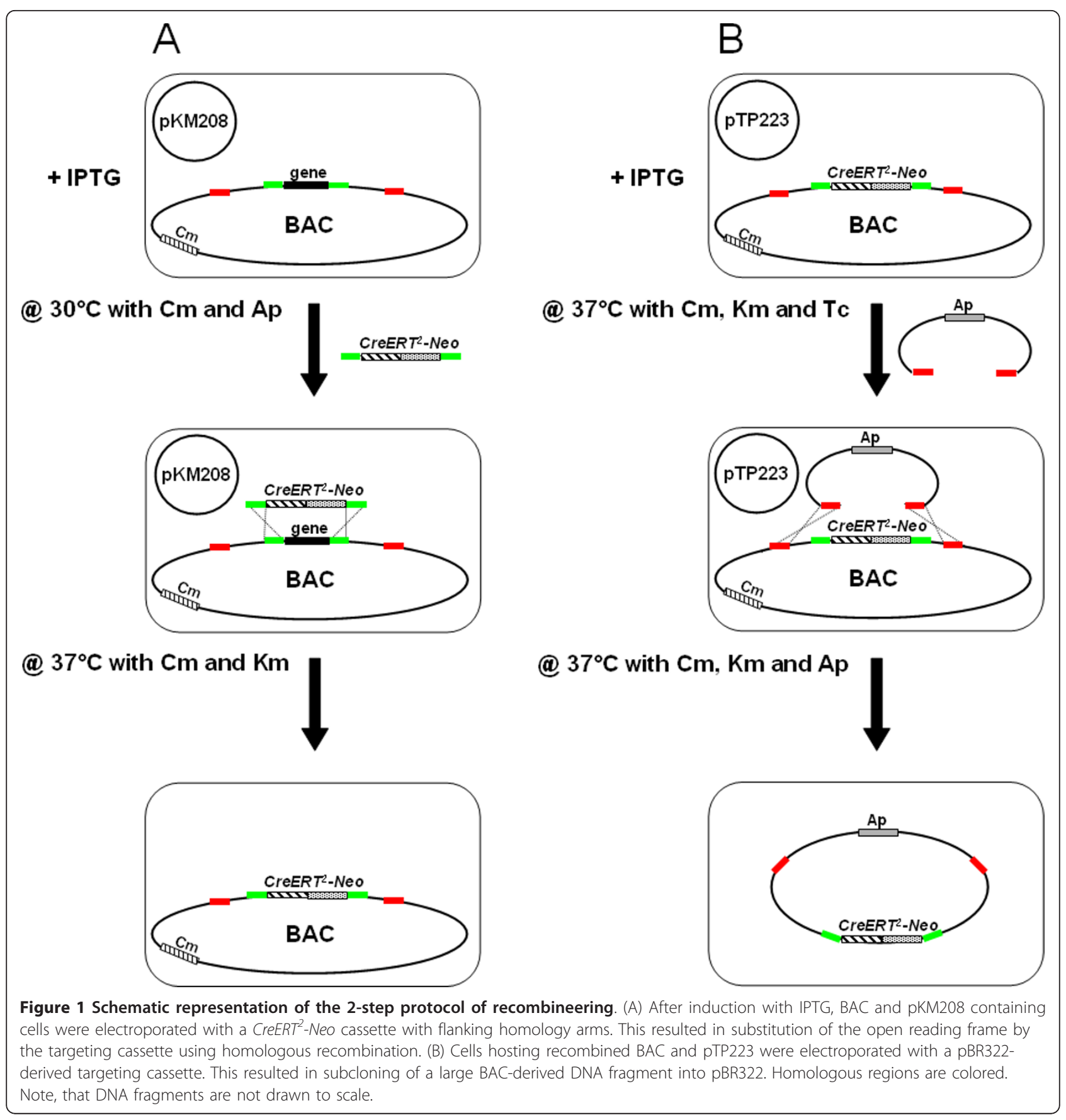

Pulser (Bio-Rad) at $1.8 \mathrm{kV}, 200 \mathrm{Ohm}, 25 \mu \mathrm{F}$ for $\sim 4.5 \mathrm{~ms}$. Cells were resuspended in $1 \mathrm{ml} \mathrm{LB}$ broth, incubated for $1 \mathrm{~h}$ at $37^{\circ} \mathrm{C}$ on a shaker, and then plated on selective LBagar plates.

\section{Screening for recombinant clones}

Recombinant clones were screened by a junction PCR for probing the insertion of the CreERT $T^{2}$-Neo cassette, using the targeting cassette specific primer 5'-CTCCTGTCAT
CTCACCTTGC-3' and the BAC specific primer Math5_90718rev 5'-CCGGACGCATTCAACATCAC-3' (expected product size: $1.6 \mathrm{~kb}$ ). For further validation, additional junction PCRs were performed. Primers were as follows: Math5_90718rev and 5'-GGCCCGCGCTGG AGTTTC-3' (3.9 kb), Math5_90718rev and 5'-CCACTG CGGGCTCTACTTC-3' (2.9 kb), as well as with the primers 5'-CCTGACACCCTTTTAGTTAAG-3'and 5'- CCA TGAGTGAACGAACCTGGTCG-3' (2.6 kb). For gap 
repair mediated subcloning, DNA from positive clones was purified by alkaline lysis and analyzed by restriction with MssI (MBI Fermentas).

\section{Results and discussion}

To establish an easy, cheap, and fast protocol for recombination-based modification of BACs, we assessed the non-commercial plasmids pKM208 and pTP223. Both plasmids have been successfully used for engineering of bacterial chromosomes $[10,12,16]$, but have not yet been employed for the manipulation of BACs. We tested both plasmids, as their different resistance genes provide flexibility with respect to the selection markers on the targeting constructs and substrates.

\section{Replacement of the Math5 ORF using pKM208}

To probe the potential of the plasmids to modify BACs, DH10B cells containing pKM208 and RP23-328P3 were transformed with a $4 \mathrm{~kb} C r e E R T^{2}$-Neo cassette with flanking homology arms of $708 \mathrm{bp}$ and $372 \mathrm{bp}$ (Figure 1A). Only IPTG induced cells gave rise to colonies on double selecting plates $(\mathrm{Cm}$ and $\mathrm{Km})$, confirming previous data on the tightly controlled gene expression from this vector [12]. Correct homologous recombination was verified by a junction PCR (Figure 2). 13 out of 50 colonies (26\%) were positive (data not shown). One positive clone was further validated by three additional junction PCRs (Figure 2) and sequencing of the resulting products. To prevent undesired subsequent recombination events in the modified $\mathrm{BAC}$, the temperature-sensitivity of the low-copy origin pSC101 was exploited. After heat induction, loss of pKM208 was demonstrated by the lack of Ap resistance (data not shown). These results demonstrate that pKM208 is well suited for homologous recombination using a BAC template and a plasmid-derived substrate.

\section{Subcloning of DNA from the BAC using PTP223}

It is often advisable to use only part of a BAC to generate transgenic organisms. This will prevent expression of additional genes residing in the $\mathrm{BAC}$, which would result in increased gene dose, often entailing abnormal phenotypes $[22,23]$. This can be achieved by two different approaches. The desired transcriptional unit can be released using appropriate restriction enzymes. Alternatively, it can be subcloned by gap repair using pBR322 [19], avoiding tedious gel-purification. We therefore tested next, whether the plasmids could mediate gap repair-based subcloning. For this purpose, primers were designed with a 50 nucleotide long sequence homologous to the target sequence in the BAC, an MssI site, and 20 nucleotides, that match to pBR322 [19]. The MssI sites were added for easy release of the entire insert for transgenic approaches. This time we tested pTP223 (Figure 1B).

DH10B cells containing the modified BAC and pTP223 were transformed with the PCR-generated pBR322-derived targeting cassette to subclone a $42 \mathrm{~kb}$ fragment containing the modified transcription unit (Math5::CreERT ${ }^{2}$ ). 24 colonies from induced cells were analyzed by a plasmid preparation followed by restriction with MssI. This resulted in 2 putative positive clones, which were confirmed by restriction using HindIII (Figure 3). The low efficiency of homologous recombination compared to our replacement experiment and a previous report [24] is likely due to the large size of the heterologous region and the short homology arms used in this experiment. Taken together, these data demonstrate that pTP223 promotes recombination with short homology arms (50 bp in length), which is in agreement with recent data [9]. In the absence of IPTG, no transformants were observed on Ap and Km containing LB agar plates, demonstrating tight regulation of the Red operon by IPTG in this plasmid as well.

Since spontaneous loss of pTP223 has been reported [12], we tested positive clones on Tc containing LBagar. Absence of growth revealed that pTP223 was lost after recombination. This beneficial feature allows stable propagation of the constructs.

\section{Conclusions}

We report a protocol for the modification and subcloning of large BAC-DNA by the use of the non-commercial

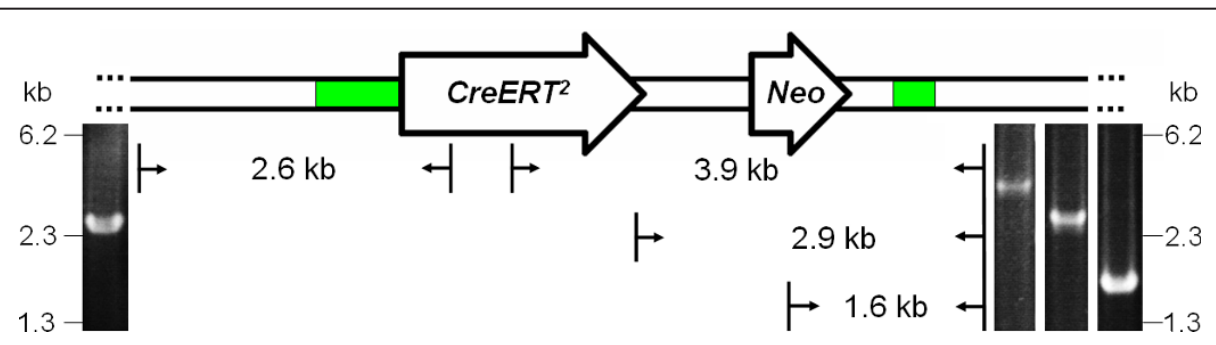

Figure 2 Analysis of the modified BAC by junction PCRs. Schematic representation of the performed junction PCRs is depicted. The CreERT ${ }^{2}$ Neo targeted region of the BAC with the corresponding primer binding sites (arrows) and the expected sizes of the PCR products are indicated. Homologous regions are depicted in green. Agarose gel electrophoresis demonstrated that all four junction PCRs yielded products of the correct size. 


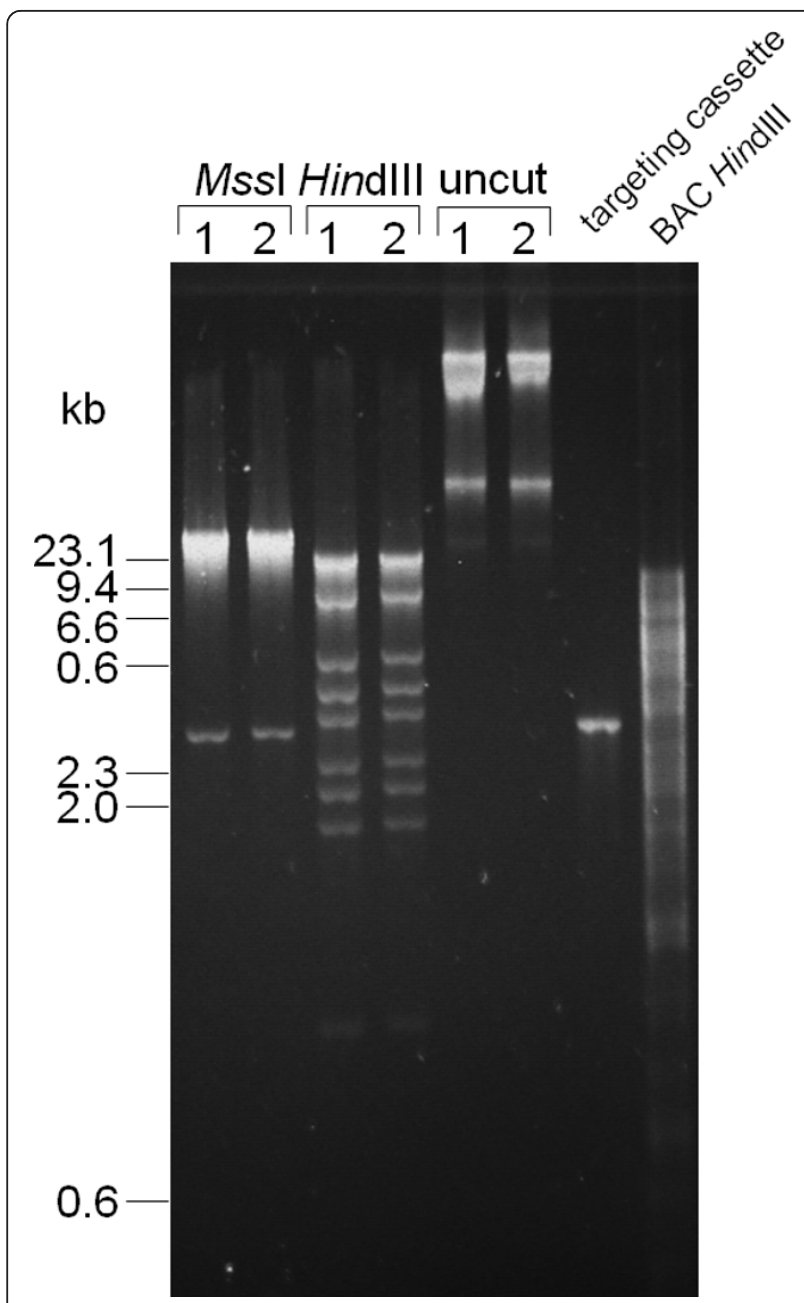

Figure 3 Analysis of the final construct. Two CreERT' ${ }^{2}$-Neo positive clones were analyzed by restriction with Mssl (lanes 1 and 2). This resulted in the $42 \mathrm{~kb}$ insert (upper band) and the $2.8 \mathrm{~kb}$ long backbone (lower band). The restriction of the two constructs with Hindlll resulted in the expected restriction pattern of $17.9 \mathrm{~kb} 7.9 \mathrm{~kb}$, $4.5 \mathrm{~kb}, 3.6 \mathrm{~kb}, 3.1 \mathrm{~kb}, 2.5 \mathrm{~kb}, 2.2 \mathrm{~kb}, 1.9 \mathrm{~kb}$ and $1 \mathrm{~kb}$ (lanes 3 and 4). Uncut clones are shown in lanes 5 and 6 . In lane 7, the PCR generated targeting cassette of $2.9 \mathrm{~kb}$ is shown, which has almost the same size as the $2.8 \mathrm{~kb}$ released backbone after restriction with Mssl. The restriction of the CreERT ${ }^{2}$-Neo targeted BAC RP23-328P3 with Hindlll resulted in fragments ranging from $13 \mathrm{bp}$ to $14.9 \mathrm{~kb}$ (lane 8). The correct restriction pattern for both Mssl and HindIII demonstrated successful targeting and subcloning of the final construct.

plasmids pKM208 and pTP223. The protocol sidesteps restriction and gel-purification of large DNA fragments. Furthermore, no BAC isolation and transformation into other strains like DY380, EL250 and EL350 is required [19]. Both plasmids are available at addgene.com and are an example for the high potential of shared sources to establish and adapt low cost protocols for everybody's use.
Here, we used pKM208 for targeting the BAC with a plasmid-derived substrate and pTP223 for subcloning. This was done to demonstrate the potential of both plasmids to promote homologous recombination using BACs as template. In future studies, only one of the two plasmids is sufficient. The choice of the plasmid solely depends on the selection marker, which should be different from those present in the BAC and the DNA substrate for homologous recombination. The availability of two different selection markers renders the system very flexible and versatile. Finally, selection for these markers in the media will ensure recombineering potential in all cells of the culture.

\section{Acknowledgements}

$\mathrm{HH}$ was supported by a stipend from the PhD program Hearing of the State of Lower Saxony. Financial support was provided by a DFG grant to HGN (No428 8/1) and the EWE Stiftung to HGN.

\section{Author details}

'Department of Neurogenetics, Institute of Biology and Environmental Sciences, Carl von Ossietzky University, Carl-von-Ossietzky-Straße 9-11, 26129 Oldenburg, Germany. ${ }^{2}$ Research Center Neurosensory Science, Carl von Ossietzky University Oldenburg, Carl-von-Ossietzky-Straße 9-11, 26129 Oldenburg, Germany.

\section{Authors' contributions}

$\mathrm{HH}$ conceived and carried out the experiments and drafted the manuscript. HGN discussed the results with $\mathrm{HH}$ and helped to draft the manuscript. Both authors read and approved the final manuscript.

\section{Competing interests}

The authors declare that they have no competing interests.

Received: 14 October 2011 Accepted: 20 March 2012

Published: 20 March 2012

\section{References}

1. Shizuya H, Birren B, Kim UJ, Mancino V, Slepak T, Tachiiri Y, Simon M: Cloning and stable maintenance of 300-kilbase-pair fragments human DNA in Escherichia col using an F-factor-based vector. Proc Natl Acad Sci USA 1992, 89:8794-8797.

2. Ioannou PA, Amemiya CT, Garnes J, Kroisel PM, Shizuya H, Chen C, Batzer MA, de Jong PJ: A new bacteriophage P1-derived vector or the propagation of large human DNA fragments. Nat Genet 1994, 6:84-89.

3. Marra MA, Kucaba TA, Dietrich NL, Green ED, Brownstein B, Wilson RK, McDonald KM, Hillier LW, McPherson JD, Waterston RH: High throughput fingerprint analysis of large-insert clones. Genome Res 1997, 7:1072-1084

4. Kelley JM, Field CE, Craven MB, Bocskai D, Kim UJ, Rounsley SD, Adam MD High throughput direct end sequencing of BAC clones. Nucleic Acids Res 1999, 27:1539-1546.

5. Copeland NG, Jenkins NA, Court DL: Recombineering: a powerful new tool for mouse functional genomics. Nat Rev Genet 2001, 2:769-779.

6. Court DL, Sawitzke JA, Thomason LC: Genetic engineering using homologous recombination. Ann Rev Genet 2002, 36:361-388.

7. Zhang Y, Buchholz F, Muyrers JPP, Stewart AF: A new logic for DNA engineering using recombination in Escherichia col. Nat Genet 1998, 20:123-128.

8. Yu D, Ellis HM, Lee EC, Jenkins NA, Copeland NG, Court DL: An efficient recombination system for chromosome engineering in Escherichia col. Proc Natl Acad Sci USA 2000, 97:5978-5983.

9. Potetee AR: What makes the bacteriophage lambda Red system useful for genetic engineering: molecular mechanism and biological function. FEMS Microbiol Lett 2001, 201:9-14. 
10. Murphy KC: Use of bacteriophage lambda recombination functions to promote gene replacement in Escherichia col. J Bacteriol 1998, 180:2063-2071.

11. Datsenko KA, Wanner BL: One-step inactivation of chromosomal genes in Escherichia col K-12 using PCR products. Proc Natl Acad USA 2000, 97:6640-6645.

12. Murphy KC, Campellone KG: Lambda Red-mediated recombinogenic engineering of enterohemorrhagic and enteropathogenic E. coli. BMC Mol Biol 2003, 4:11.

13. Rossi MS, Paquelin A, Ghigo JM, Wandersman C: Haemophoremediated signal transduction across the bacterial cell envelope in Serratia marcescen: the inducer and the transported substrate are different molecules. Mol Microbiol 2003, 48:1467-1480.

14. Lesic B, Bach S, Ghigo JM, Dobrindt U, Hacker J, Carniel E: Excision of the high-pathogenicity island of Yersinia pseudotuberculosi requires the combined actions of its cognate integrase and Hef, a new recombination directionality factor. Mol Microbiol 2004, 52:1337-1348.

15. Husseiny MI, Hensel M: Rapid method for the construction of Salmonella enterica Serovar Typhimuriu vaccine carrier strains. Infect Immun 2005, 73:1598-1605.

16. Ranallo RT, Barnoy $S$, Thakkar S, Urick T, Venkatesan MM: Developing live Shigell vaccines using $\lambda$ Red recombineering. FEMS Immunol Med Microbiol 2006, 47:462-469.

17. Liang R, Liu J: Scarless and sequential gene modification in Pseudomona using PCR product flanked by short homology regions. BMC Microbiol 2010, 10:209.

18. Muyrers JP, Zhang Y, Testa G, Stewart AF: Rapid modification of bacterial artificial chromosomes by ET-recombination. Nucleic Acids Res 1999, 27:1555-1557.

19. Lee EC, Yu D, Martinez de Velasco J, Tessarollo L, Swing DA, Court DL, Jenkins NA, Copeland NG: A highly efficient Escherichia coli-based chromosome engineering system adapted for recombinogenic targeting and subcloning of BAC DNA. Genomics 2001, 73:56-65.

20. Poteete AR, Fenton AC: Lambda red-dependent growth and recombination of phage P22. Virology 1984, 134:161-167.

21. Thomson JM, Parrot WA: pMECA: a cloning plasmid with 44 unique restriction sites that allows selection of recombinants based on colony size. Biotechniques 1998, 24:922-924.

22. Salahpour A, Ramsey AJ, Medvedev IO, Kile B, Sotnikova TD, Holmstrand E, Ghisi V, Nicholls PJ, Wong L, Murphy K, Sesack SR, Wightman RM,

Gainetdinov RR, Caron MG: Increased amphetamine-induced hyperactivity and reward in mice overexpressing the dopamine transporter. Proc Natl Acad USA 2008, 105:4405-4410.

23. Belichenko NP, Belichenko PV, Kleschevnikov AM, Salehi A, Reeves RH, Mobley WC: The "Down syndrome critical region" is sufficient in the mouse model to confer behavioral, neurophysiological, and synaptic phenotypes characteristic of Down syndrome. J Neurosci 2009, 29:5938-5948.

24. Zha J, Chen X, Li C, Zhu M, Ding G, He W: One-step construction of lentiviral reporter using red-mediated recombination. Mol Biotechnol 2011, 49:278-282.

doi:10.1186/1756-0500-5-156

Cite this article as: Hartwich and Nothwang: An easy and versatile 2step protocol for targeted modification and subcloning of DNA from bacterial artificial chromosomes using non-commercial plasmids. BMC Research Notes 2012 5:156.

\section{Submit your next manuscript to BioMed Central and take full advantage of:}

- Convenient online submission

- Thorough peer review

- No space constraints or color figure charges

- Immediate publication on acceptance

- Inclusion in PubMed, CAS, Scopus and Google Scholar

- Research which is freely available for redistribution

Submit your manuscript at www.biomedcentral.com/submit
C Biomed Central 